\section{Raquel Rodríguez de Pablos Carmen García-Ruiz \\ Antonio L. Crego \\ M. Luisa Marina}

Departamento de Química Analítica, Facultad de Química, Universidad de Alcalá, Alcalá de Henares (Madrid), Spain

\title{
Separation of etodolac enantiomers by capillary electrophoresis. Validation and application of the chiral method to the analysis of commercial formulations
}

\begin{abstract}
Separation of etodolac enantiomers, which exhibit different biological activity and pharmacokinetic profiles, has been achieved using the randomly substituted (2-hydroxy)propyl- $\beta$-cyclodextrin (HP- $\beta-C D$ ) as chiral selector in capillary electrophoresis. The selection of this CD was made after screening of different CD derivatives of neutral and anionic nature. The effect on the enantioresolution of the buffer concentration and of the degree of substitution (DS) and concentration of the CD as well as of instrumental parameters, such as the capillary temperature and the separation voltage, were studied. The highest resolution of etodolac enantiomers was around 2.5 using $100 \mathrm{~mm}$ phosphate buffer $(\mathrm{pH} 7.0$ ) with $20 \mathrm{~mm} \mathrm{HP-} \beta-\mathrm{CD}$ (DS 4.2) and UV detection at $225(10) \mathrm{nm}$ with a reference wavelength at $360(50) \mathrm{nm}$. Validation of the chiral method in terms of selectivity, linearity, precision (instrumental repeatability, method repeatability, intermediate precision), and the limits of detection and quantitation allowed to evaluate its quality to the analysis of etodolac enantiomers in different pharmaceutical preparations containing racemic etodolac.
\end{abstract}

Keywords: Capillary electrophoresis / Chiral separation / Cyclodextrins / Enantiomers / Etodolac / (2-Hydroxy)propyl- $\beta$-cyclodextrin

DOI 10.1002/elps.200410097

\section{Introduction}

Etodolac (Fig. 1) is a nonsteroidal anti-inflammatory drug (NSAID) that exhibits anti-inflammatory, analgesic, and antipyretic activities in animal models. This drug is marketed as a racemic mixture of etodolac in which the S-form is biologically active [1]. However, it has been reported very recently that the $R$-enantiomer exhibits pharmacological activity in patients suffering from leukemia (B-cell chronic lymphocytic leukemia) [2]. Additionally, the more extensive binding of $S$-etodolac compared to the $R$-form to human serum albumin under physiological conditions has also been reported [3, 4]. On the other hand, enantioselectivity was reflected in the pharmacoki-

Correspondence: Dr. M. Luisa Marina, Departamento de Química Analítica, Facultad de Química, Universidad de Alcalá, Ctra. Madrid Barcelona Km. 33.600, E-28871 Alcalá de Henares (Madrid), Spain

E-mail: mluisa.marina@uah.es

Fax: +34-91-8854971

Abbreviations: AC- $\beta-\mathbf{C D}$, acetylated- $\beta$-cyclodextrin; ANOVA analysis of variance; CE- $\beta-C D$, carbocyethylated $\beta-C D ; \mathbf{C M}-\beta-$ CD, carboxymethylated $\beta-C D$; DS, degree of substitution; HBen- $\beta$-CD ${ }^{\circledR}$, (2-hydroxy)-buten-3-yl- $\beta-C D$; HP- $\beta$-CD, 2-hydroxypropylated $\beta-C D$; RAMEG, randomly methylated $\beta-C D$; Succ- $\beta-C D$, succinylated $\beta-C D$

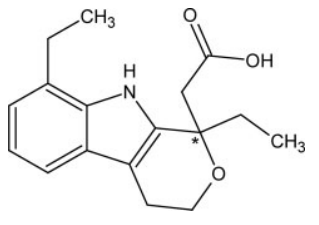

Figure 1. Basic structure of etodolac $(( \pm)-1,8$-diethyl-1,3,4,9tetrahydropyrano-[3,4-b]indole1-acetic acid); (*) indicates the chiral center.

netics of etodolac enantiomers since the plasma concentrations of the $R$-enantiomer greatly exceeded those of the $S$-form $[5,6]$.

Several methods for the separation of etodolac enantiomers by high-performance liquid chromatography (HPLC) have been reported showing the interest of the development of chrial methods for the analysis of etodolac [7-10]. However, the capability of capillary electrophoresis (CE) as separation technique for drug enantiomers is widely recognized nowadays. Hundreds of scientific papers, a wide number of reviews, several dedicated issues of international journals [11-15] and even a book [16] have been published reporting a large number of enantiomeric separations of drugs by CE. However, until now, very few methods for the baseline separation of etodolac enantiomers have been reported. Using vancomycin as chiral selector, Fanali et al. [17] achieved the separation of the enantiomers of etodolac in about $12 \mathrm{~min}$ and detected 
them by mass spectrometry with electrospray ionization. Vancomycin is a glycopeptide-type macrocyclic antibiotic with a limited $\mathrm{pH}$ working range $(4<\mathrm{pH}<8)$, adsorbs to the wall of untreated fused-silica capillaries and has strong absorption in the UV-Vis region. On the other hand, a permethylated $\gamma$-CD was used as chiral selector by Mayer and Schurig [18] in capillary electrochromatography. They showed the usefulness of open-tubular columns for the enantioseparation of NSAIDs including etodolac. However, only with the permethylated $\gamma-C D$ (Chirasil-Dex) it was possible to achieve a resolution of 1.6 for etodolac enantiomers in $30 \mathrm{~min}$.

Our goal was to develop a chiral separation method by CE using cyclodextrins (CDs) as chiral selectors due to their potential for chiral separations, commercial availability, stability, and easy use in comparison with other chiral selectors as, for example, macrocyclic antibiotics or proteins, which present similar practical problems. Then, in this work, we have made a screening of different CD derivatives of neutral and anionic nature to select the most appropriate chiral selector for the enantioresolution of etodolac by CE. With the slected chiral selector, effect on the enantioresolution of the buffer concentration, degree of substitution (commercial origin) of the chiral selector, and concentration of the CD, as well as instrumental parameters, such as temperature and the separation voltage, have been studied to achieve the best resolution of etodolac enantiomers. Finally, the validation of the chiral method and its use to quantify the amount of etodolac in different pharmaceutical preparations have also been performed.

\section{Materials and methods}

\subsection{Reagents and samples}

All reagents employed for the preparation of the separation buffers were of analytical grade. Disodium hydrogen phosphate hydrate and sodium acetate were supplied by Panreac (Barcelona, Spain). Dimethyl sulfoxide (DMSO) was from Scharlab (Barcelona, Spain). Sodium hydroxide, sodium dihydrogen phosphate dihydrate, and ortophosphoric acid were from Merck (Darmstadt, Germany). $\beta$-Cyclodextrin ( $\beta-C D)$, randomly methylated $\beta$-cyclodextrin (RAMEB, degree of substitution (DS), average number of substituents on one cyclodextrin ring $\sim 12-14), \quad 2$-hydroxypropylated- $\beta$-cyclodextrin (HP- $\beta$ $\mathrm{CD}, \mathrm{DS} \sim 4.2)$, carboxymethylated $\beta$-cyclodextrin (CM- $\beta$ $C D, D S \sim 3$ ), and succinylated $\beta$-cyclodextrin (Succ- $\beta$ $C D, D S \sim 3$ ) were purchased from Fluka (Buchs, Switzerland). (2-Hydroxy)-buten-3-yl- $\beta$-cyclodextrin (HBen- $\beta$ $\left.C D^{\circledR}, \quad D S \sim 5\right)$, carboxyethylated- $\beta$-cyclodextrin (CE- $\beta$ -
CD, DS $\sim 3$ ), carboxyethylated $\gamma$-cyclodextrin (CE- $\gamma-C D$, $D S \sim 4)$, acetylated $\beta$-cyclodextrin (Ac- $\beta-C D, D S \sim 7$ ), acetylated $\gamma$-cyclodextrin (Ac- $\gamma-C D, D S \sim 7$ ), carboxymethylated $\gamma$-cyclodextrin (CM- $\gamma-\mathrm{CD}, \mathrm{DS} \sim 3)$, $\gamma$-cyclodextrin $(\gamma-C D)$, and HP- $\beta-C D(D S \sim 3)$ were from Cyclolab (Budapest, Hungary). In addition, HP- $\beta-C D(D S \sim 4.7)$ and RAMEB (DS 10.5-14.7) were also obtained from Sigma (Madrid, Spain). Water used to prepare solutions was purified with a Milli-Q system from Millipore (Bedford, MA, USA). All solutions were filtered prior to use through $0.45 \mu \mathrm{m}$ pore size disposable nylon filters from Sugelabor (Madrid, Spain). Etodolac was from Sigma. The pharmaceutical tablets analyzed were obtained in a pharmacy of Ismira (Turkey). Table 1 shows the composition of these formulations.

Table 1. Composition of the three different commercial formulations analyzed

\section{Commercial Composition}

formulation

Tablet A Etodolac (200 mg per tablet), $\mathrm{Fe}_{2} \mathrm{O}_{3}$ and $\mathrm{TiO}_{2}$

Tablet $\mathrm{B} \quad$ Etodolac (300 mg per tablet), $\mathrm{Fe}_{2} \mathrm{O}_{3}, \mathrm{FeO}$, and $\mathrm{TiO}_{2}$

Tablet $\mathrm{C} \quad$ Etodolac (300 mg per tablet), $\mathrm{Fe}_{2} \mathrm{O}_{3}$ and $\mathrm{TiO}_{2}$

\subsection{Apparatus}

All experiments were performed on a $\mathrm{HP}^{3 \mathrm{D}} \mathrm{CE}$ system (Hewlett-Packard, Waldbronn, Germany) equipped with an on-column diode array detector (DAD). Instrument control and data acquisition was performed with the HP 3D-CE ChemStation software. Separations were performed on uncoated fused-silica capillaries of $50 \mu \mathrm{m}$ ID and $375 \mu \mathrm{m}$ OD, purchased from Composite Metal Services (Worcester, England). Capillaries had a total length of $58.5 \mathrm{~cm}$ and $50 \mathrm{~cm}$ to the detector. The capillary temperature was $15^{\circ} \mathrm{C}$ and UV detection was performed at $225 \mathrm{~nm}$ with a bandwidth of $10 \mathrm{~nm}$ using a reference wavelength of $360 \mathrm{~nm}$ with a bandwidth of $50 \mathrm{~nm}$ and a response time of $0.3 \mathrm{~s}$. To adjust the $\mathrm{pH}$ of the separation buffers, a 744 pH-meter from Metrohm (Herisau, Switzerland) was used.

\subsection{Procedures}

Before its first use, a new capillary was flushed ( 1 bar) with $1 \mathrm{M} \mathrm{NaOH}$ for $30 \mathrm{~min}$, followed by $30 \mathrm{~min}$ with water and 60 min with buffer. Between introduction of samples, the capillary was conditioned with $0.1 \mathrm{M} \mathrm{NaOH}$ for $1 \mathrm{~min}$ followed by the separation buffer for 2 min. Injections were made by pressure ( $50 \mathrm{mbar}$ for $3 \mathrm{~s}$ of sample followed by 50 mbar for $3 \mathrm{~s}$ of buffer), and the applied voltage was 
$20 \mathrm{kV}$. Buffer separation solutions were prepared by dissolving the same amount of the acid and basic components in order to get the desired $\mathrm{pH}$, the $\mathrm{p} K_{\mathrm{a}}$ of the selected acid. The appropriate amount of each CD was weighed and dissolved into these buffer solutions at a final concentration of $20 \mathrm{~mm}$. Stock solutions were prepared by dissolving the appropriate amount of etodolac in DMSO to achieve a final concentration of $2000 \mathrm{mg} / \mathrm{L}$. These solutions were diluted in 1:1 v/v water/DMSO to get diluted solutions with concentrations of etodolac between 10 and $200 \mathrm{mg} / \mathrm{L}$ (5 and $100 \mathrm{mg} / \mathrm{L}$ of each enantiomer). Sample solutions of the three commercial formulations analyzed were prepared by crushing and mixing homogeneously five tablets of each commercial formulation and weighing about $0.1 \mathrm{~g}(0.11-0.13 \mathrm{~g})$ of the resultant powder which was dissolved in DMSO at a final concentration of $5000 \mathrm{mg} / \mathrm{L}$. These sample solutions were diluted $1: 1 \mathrm{v} / \mathrm{v}$ in water/DMSO to get solution concentrations of $100 \mathrm{mg} / \mathrm{L}$. All solutions (buffers, standards, and samples) were filtered through $0.45 \mu \mathrm{m}$ pore size nylon filter membranes and sonicated before use.

\subsection{Data treatment}

Resolution was obtained from the ChemStation software using the equation $R s=1.18 t_{2}-t_{1} / w_{1 / 2,1}+w_{1 / 2,2}$ where $t_{1}$ and $t_{2}$ are the migration times of etodolac enantiomers and $w_{1 / 2,1}, w_{1 / 2,2}$ are their peak widths at half height. Limits of detection (LODs; $3 s_{\mathrm{a}} / \mathrm{b}$ ) and quantitation (LOQs, $10 s_{a} / b$ ) were determined from the standard error of the intercept $\left(s_{\mathrm{a}}\right)$ and the slope $(b)$ of the calibration curve obtained by analysis of variance (ANOVA) [19]. Control graphs elaborated for stability studies were made plotting corrected peak areas as a function of time. The central values, $X$, were calculated as the averaged value of six repeated runs, and the control limits (which enable to visualize the values in and out of control) were calculated as $X \pm 3 s$ where $s$ is the standard deviation of the six replicate values [20]. Experimental data analysis and parameters were calculated using Excel Microsoft $X P^{\circledR}$ and Statgraphics Plus ${ }^{\circledR}$ Version 5.0 softwares.

\section{Results and discussion}

\subsection{Method optimization}

The crucial step to achieve an enantiomeric separation is the choice of the chiral selector. CDs are the favourite chiral selectors in CE and they have shown to separate the enantiomers of a huge amount of chiral drugs. Due to their availability, stability, and potential, we selected different CD derivatives of neutral and anionic nature (see
Table 2) for screening their capability as chiral selectors for etodolac enantiomers. All these CDs were used in $50 \mathrm{~mm}$ phosphate buffer at $\mathrm{pH}$ 7.0. This buffer was used because it enabled the larger difference between the EOF and etodolac signals (the $\mathrm{p} K_{\mathrm{a}}$ of etodolac is 4.65). In addition, the buffer $\mathrm{pH}$ is similar to physiological conditions which is desirable for pharmacokinetic studies where biological fluids at this $\mathrm{pH}$ (e.g., blood) may be analyzed.

As shown in Table 2, the anionic cyclodextrins CM- $\gamma-C D$, CM- $\beta-C D, C E-\gamma-C D, C E-\beta-C D$, and Succ- $\beta-C D$ and the neutral cyclodextrins $\beta-C D$, RAMEB from Sigma, Ac- $\beta$ $C D$, and $A c-\gamma-C D$ (all of them at a concentration of $20 \mathrm{~mm}$ ) did not show enantioresolution power for etodolac. With 20 mм RAMEB from Fluka or HBen- $\beta-C D^{\circledR}$ poor enantioresolutions were observed $(R s<0.7)$. The highest enantioresolutions were obtained for the neutral HP- $\beta-C D$ and $\gamma$-CD at a concentration of $20 \mathrm{~mm}$ in phosphate buffer at pH 7.0 (see Table 2). As a consequence, we selected HP$\beta-C D$ as chiral selector for the separation of etodolac enantiomers because it is less expensive than $\gamma-C D$.

Table 2. Enantioresolutions (Rs) of etodolac enantiomers obtained with the different CD derivatives studied at a $20 \mathrm{~mm}$ concentration

\begin{tabular}{|c|c|c|}
\hline \multicolumn{2}{|c|}{ CD (commercial supplier) } & Enantioresolution \\
\hline Neutral CDs & $\begin{array}{l}\beta-C D \text { (Fluka) } \\
\text { RAMEB (Sigma) } \\
\text { RAMEB (Fluka) } \\
\text { HP- } \beta-C D \text { (Cyclolab) } \\
\text { HBen- } \beta-C D{ }^{\circledR} \text { (Cyclolab) } \\
\text { Ac- } \beta-C D \text { (Cyclolab) } \\
\gamma-C D \text { (Cyclolab) } \\
\text { Ac- } \gamma-C D \text { (Cyclolab) }\end{array}$ & $\begin{array}{l}- \\
- \\
+ \\
++ \\
+ \\
- \\
++ \\
-\end{array}$ \\
\hline Anionic CDs & $\begin{array}{l}\text { Succ- } \beta-C D \text { (Fluka) } \\
\text { CM- } \beta-C D \text { (Fluka) } \\
\text { CE- } \beta-C D \text { (Cyclolab) } \\
\text { CM- } \gamma-C D \text { (Cyclolab) } \\
\text { CE- } \gamma-C D \text { (Cyclolab) }\end{array}$ & $\begin{array}{l}- \\
- \\
- \\
- \\
-\end{array}$ \\
\hline
\end{tabular}

,$- R_{\mathrm{s}} \sim 0 ;+, R_{\mathrm{s}}<0.7 ;++, 0.7 \leq R_{\mathrm{s}} \leq 1$

With the selected CD, the influence on enantiomeric resolution of the temperature and separation voltage was studied to choose the most appropriate values of these parameters. The variation of the resolution for etodolac enantiomers as a function of the capillary temperature in the range of $15-45^{\circ} \mathrm{C}$. showed that the resolution gradually decreases as the temperature increases. This effect was observed previously with the same CD derivative by our research group [21] and could be attributed to the increase in the stability of selector-selectand complexes 
that takes place when the temperature is decreased [16, $21,22]$. Therefore, all subsequent separations were performed at $15^{\circ} \mathrm{C}$. However, a low influence of the separation voltage on the enantioresolution of drugs is generally obtained. For etodolac enantiomers a similar enantioresolution was obtained for 15 and $20 \mathrm{kV}$ whereas the resolution decreased for $30 \mathrm{kV}$. Since the migration times decreased when increasing the applied voltage, $20 \mathrm{kV}$ of separation voltage was used in our experiments.

The effect of the buffer concentration on the separation of etodolac enantiomers was investigated by using different concentrations $(40,50,80$, and $100 \mathrm{~mm})$ phosphate buffer containing $20 \mathrm{~mm} \mathrm{HP-} \beta-\mathrm{CD}$. As it can be seen in Fig. 2, there is a linear increment of the enantioresolution with the phosphate buffer concentration from 40 to $100 \mathrm{~mm}$. This can be explained because when the buffer concentration increases the solute-wall interactions and the undesirable effects of electrodispersion are minimized [16]. Therefore, $100 \mathrm{~mm}$ phosphate buffer at $\mathrm{pH} 7$ $(\sim 140 \mu \mathrm{A})$ was used for further experiments.

The influence of the concentration and the degree of substitution of HP- $\beta-C D$ (commercial origin) in the selected buffer was also studied. The commercial origin of the chiral selector in the separation buffer was found to be a very decisive factor influencing the enantiomeric resolution of the etodolac enantiomers. This is because

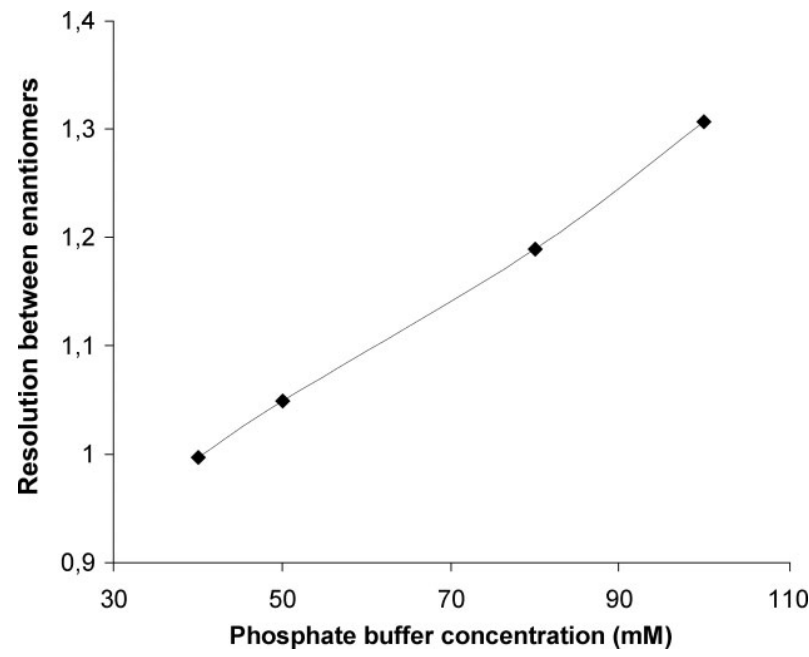

Figure 2. Effect of the buffer concentration on the enantioresolution of etodolac for a phosphate buffer $(\mathrm{pH} 7)$ with $20 \mathrm{~mm}$ HP- $\beta-C D$ (Cyclolab) as chiral selector. CE conditions: temperature, $15^{\circ} \mathrm{C}$; untreated fused-silica capillary, $58.5 \mathrm{~cm}(50 \mathrm{~cm}$ to the detector window) $\times 50 \mu \mathrm{m}$ ID; applied voltage, $20 \mathrm{kV}$; injection, $50 \mathrm{mbar} \times 3 \mathrm{~s}$. UV detection at $230 \mathrm{~nm}$.
HP- $\beta-C D$ is a randomly substituted CD manufactured in a different way by the three different suppliers which provide different DSs (see Section 2). Thus, depending on the DS, the substitution patterns can be different and even side chain substitution (e.g., 2-(2'-hydroxy)propoxy) propyl substituents) is possible. In addition, the DS depends on the chemical reaction (used base, low/high temperature) and large differences between batches and production sites may be obtained under some conditions. Due to these problems, a trend in chiral analysis by CE is the use of single-isomer CDs, which are able to achieve higher reproducibility and selectivity than randomly substituted CDs [23]. However, it is important to note that $\mathrm{HP}-\beta-\mathrm{CD}$, which has been shown to be the best chiral selector for etodolac, is not a single isomer (Cyclolab produces the single isomer monoHp- $\beta$-CD but its aqueous solutility is very poor, $<0.05 \mathrm{~g} / 100 \mathrm{~cm}^{3}$, being not useful in aqueous $\mathrm{CE}$ ). For this reason, we studied the effect of the concentration of this CD from three different commercial suppliers on the resolution of etodolac enantiomers. This study was performed because the concentration of the chiral selector affects directly the chiral properties [21, 24]. As can be seen in Fig. 3, when varying the concentration of HP- $\beta-C D$ of the three different commercial origins from 10 to $60 \mathrm{~mm}$, the maximum enantioresolution for etodolac was observed at a $20 \mathrm{~mm} C D$ concentration. In addition, HP- $\beta-C D$ from Fluka (DS 4.2) gets always the best enantioresolution values for all the concentrations studied. As a consequence, this concentration of the HP- $\beta-C D$ (DS 4.2) was chosen for the enantiomeric separation of etodolac.

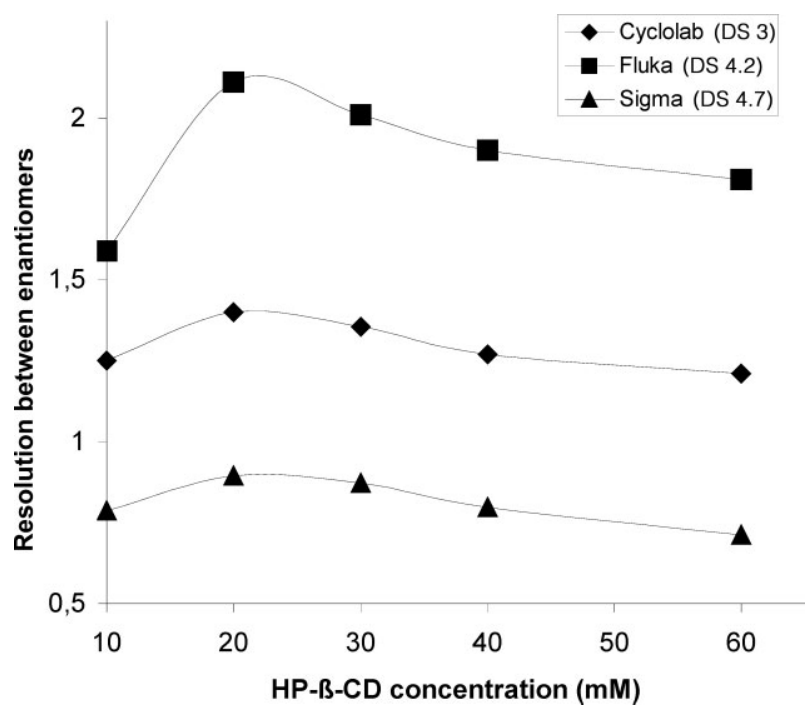

Figure 3. Influence of the concentration and the DS (commercial origin) effect of the HP- $\beta-C D$ in $100 \mathrm{~mm}$ phosphate buffer ( $\mathrm{pH} 7$ ) on the enantioresolution of etodolac. CE conditions as in Fig. 2. 
The detection conditions for etodolac enantiomers were also studied in this work. As it is known, the response time of the detector affects the baseline noise and the enantioresolution. In this case, an increase in the response time from 0.1 to $0.3 \mathrm{~s}$ leads to a decrease in the noise (from $0.79 \times 10^{-4}$ to $0.43 \times 10^{-4}$ A.U.) whereas enantioresolution was maintained (Rs 2.1). However, for a response time of $1.0 \mathrm{~s}$ although the noise decreased, the data acquired was not enough to show any enantioresolution. As a result, a response time of $0.3 \mathrm{~s}$ was used to afford the lowest noise (highest signal-to-noise ratio, $\mathrm{S} / \mathrm{N}$ ) with an adequate resolution. In addition, the optimization of the analytical wavelength value, the reference wavelength, and the bandwidth (it will be indicated within parentheses) of those wavelengths was performed. Preliminary studies were carried out at an analytical wavelength of $230 \mathrm{~nm}(4)[18,25]$ with the lowest possible bandwidth and without reference wavelength. From the absorption spectrum of etodolac it was observed that the absorption band of maximum absorption is around $230 \mathrm{~nm}$. Then 225, 230, and $235 \mathrm{~nm}$ were used as analytical wavelengths obtaining the highest $\mathrm{S} / \mathrm{N}$ at $225 \mathrm{~nm}$. At this wavelength, the bandwidth and the reference wavelength were studied. The lowest noise and higher $\mathrm{S} / \mathrm{N}$ were obtained using $225 \mathrm{~nm}$ (10) and a reference wavelength of $360 \mathrm{~nm}$ (50). The electropherogram shown in Fig. 4 for the separation of etodolac enantiomers was obtained under these detection conditions. A resolution $>2$ for etodolac enantiomers can be observed when using $100 \mathrm{~mm}$ phosphate buffer ( $\mathrm{pH} 7.0$ ) with $20 \mathrm{~mm} \mathrm{HP}-\beta$ CD (DS 4.2).

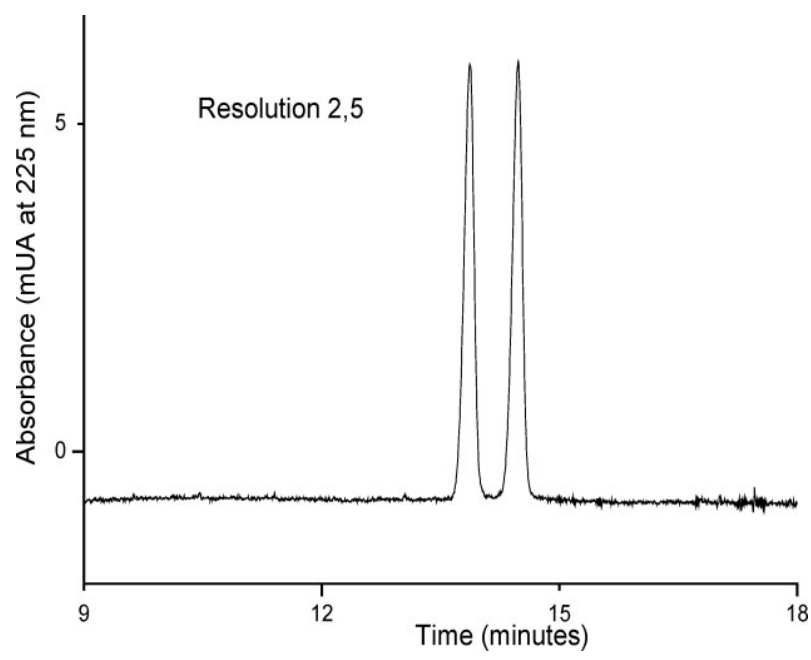

Figure 4. Electropherogram corresponding to the separation of etodolac enantiomers using $20 \mathrm{~mm} \mathrm{HP}-\beta$ CD (Fluka) in $100 \mathrm{~mm}$ phosphate buffer (pH 7). CE conditions: UV detection at 225 (10) $\mathrm{nm}$ and reference at 360 (50) $\mathrm{nm}$; time response of detector, $0.3 \mathrm{~s}$. Other conditions as in Fig. 2.

\subsection{Method validation}

Prior to the validation of the chiral method developed for etodolac the preconditioning of the capillary and the procedure for sample injection (with or without plug) were studied. A preconditioning with the separation buffer or with $0.1 \mathrm{M} \mathrm{NaOH}$ followed by separation buffer by pressure (1 bar for $2 \mathrm{~min}$ ) or voltage $(2 \mathrm{kV}$ ) showed that a voltage stage did not improve the precision (measured as RSD for migration times for six replicates of a standard solution). However, the use of $\mathrm{NaOH}$ followed of background electrolyte (BGE) gave the best precision without any loss of enantioresolution. After injection of the sample (50 mbar for $3 \mathrm{~s}$ ), a plug (50 mbar for $3 \mathrm{~s}$ ) of DMSO or separation buffer was injected. An improvement of the precision without loss in enantioresolution was observed when a plug of BGE after sample injection was used (with DMSO a decrease in the enantioresolution and precision was obtained).

The proposed analytical method for the analysis of etodolac enantiomers was validated by evaluating the quality, reliability, and consistency of its results. Nevertheless, prior to the validation, a study on sample stability was carried out. Etodolac concentrations of 10 and $100 \mathrm{mg} / \mathrm{L}$ ( 5 and $50 \mathrm{mg} / \mathrm{L}$ of each enantiomer) were prepared and then injected every day for a total of five days. As it can be seen in Fig. 5, the corrected peak areas obtained for the two independent samples analyzed (samples A and B) are included into the control limits.

The validation of the chiral CE method was made by studying the precision, linearity, LODs and LOQs, and selectivity for different commercial pharmaceutical tablets. Precision was evaluated considering the instrumental and method repeatability as well as the intermediate precision. Instrumental repeatability was determined from six repeated injections of two standard solutions at two different concentration levels (10 and $100 \mathrm{mg} / \mathrm{L}$ etodolac). In both cases, RSD values for corrected peak areas below $5 \%$ were obtained (Table 3 ). The method repeatability was assessed with six replicate standard solutions of 10 and $100 \mathrm{mg} / \mathrm{L}$ etodolac injected by triplicate on the same day. RSD values for both standard solutions were lower than $6.7 \%$ for corrected peak areas (Table 3). The intermediate precision of the method was calculated for three freshly prepared standard solutions of etodolac containing 10,50 , and $100 \mathrm{mg} / \mathrm{L}$ and injected by triplicate for five consecutive days. Table 3 shows that in this case the RSD value for corrected peak areas was lower than $8.2 \%$.

The linearity was studied plotting corrected peaks areas (Ac) as a function of analyte concentrations (c) in $\mathrm{mg} / \mathrm{L}$. Five standard solutions containing racemic etodolac from 

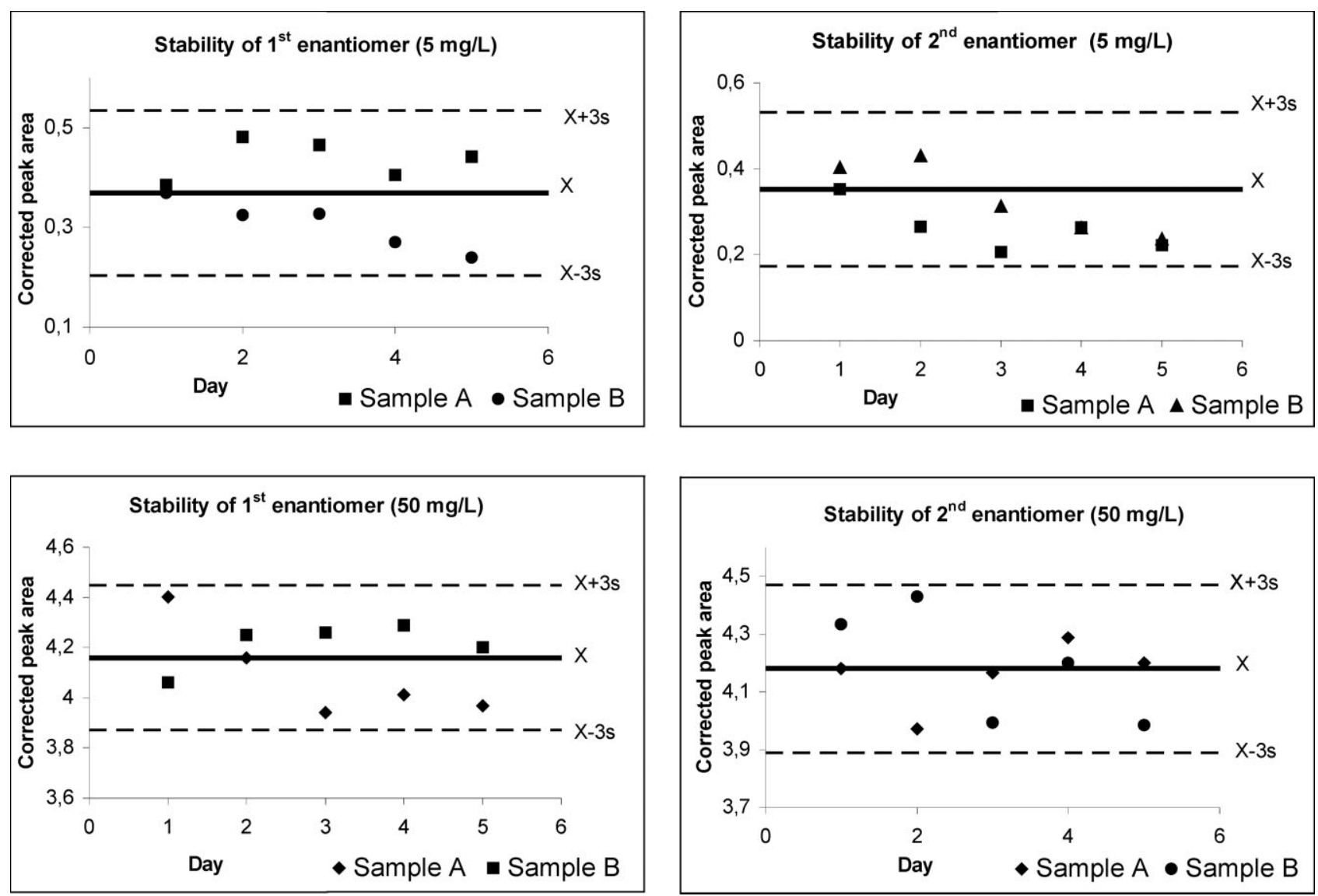

Figure 5. Study of the sample stability with 5 and $50 \mathrm{mg} / \mathrm{L}$ solutions of etodolac enantiomers using $20 \mathrm{~mm} \mathrm{HP- \beta -CD} \mathrm{(DS}$ 4.2) in $100 \mathrm{~mm}$ phosphate buffer (pH 7). Injection, sample $50 \mathrm{mbar} \times 3 \mathrm{~s}$ with a plug of BGE at $50 \mathrm{mbar} \times 3 \mathrm{~s}$. Other conditions as in Fig. 4.

Table 3. Precision of the chiral method developed for etodolac $^{\text {a) }}$

\begin{tabular}{lrll}
\hline & $\begin{array}{l}\text { Etodolac } \\
\text { concentration } \\
(\mathrm{mg} / \mathrm{L})\end{array}$ & \multicolumn{2}{c}{ RSD (\%) peak area } \\
\cline { 3 - 4 } & & $\begin{array}{l}\text { First } \\
\text { enantiomer }\end{array}$ & $\begin{array}{l}\text { Second } \\
\text { enantiomer }\end{array}$ \\
\hline $\begin{array}{l}\text { Instrumental repeatability } \\
(n=6)\end{array}$ & 10 & 4.1 & 4.3 \\
$\quad 100$ & 4.9 & 4.7 \\
$\begin{array}{l}\text { Method repeatability } \\
(n=6)\end{array}$ & 10 & 5.8 & 5.3 \\
$\begin{array}{l}\text { Intermediate precision } \\
(n=15)\end{array}$ & 100 & 6.7 & 5.4 \\
& 10 & 7.2 & 8.2 \\
& 50 & 7.3 & 7.6 \\
\hline
\end{tabular}

a) Experimental conditions as in Fig. 4

10 to $200 \mathrm{mg} / \mathrm{L}$ (each one injected in triplicate) were considered. The chiral method enabled to study separately each enantiomer, which concentrations ranged from 5 to
$100 \mathrm{mg} / \mathrm{L}$ for each enantiomer. By ANOVA we confirmed that experimental data fit properly to linear models for each one of the enantiomers (the lack of fit was always statistically smaller than the pure error, $p$-value 0.51 and 0.45 for enantiomers). The linear equations obtained were $A c=0.0668 c-0.07\left(s_{\mathrm{a}}=0.13 ; s_{\mathrm{b}}=0.0021 ; r=0.994\right)$ for the first-migrating enantiomer and $A c=0.0648 c-0.07$ $\left(s_{\mathrm{a}}=0.13 ; s_{\mathrm{b}}=0.0021, r=0.994\right)$ for the second-migrating enantiomer, where $s_{\mathrm{a}}$ is the standard error of the intercept, $s_{\mathrm{b}}$ is the standard error of the slope, and $r$ is the correlation coefficient. From calibration line parameters, LODs and LOQs for etodolac enantiomers were calculated. For both enantiomers the LOD was $5.8 \mathrm{mg} / \mathrm{L}$ and the $\mathrm{LOQ}$ was $19.4 \mathrm{mg} / \mathrm{L}$.

An adequate selectivity for the analysis of three commercial preparations was obtained with the chiral method developed for etodolac. Figure 8 shows the enantiomeric separation of etodolac for three different commercial tablets. It can be observed that the enantioresolution of etodolac is good and there are no evidence of inter- 


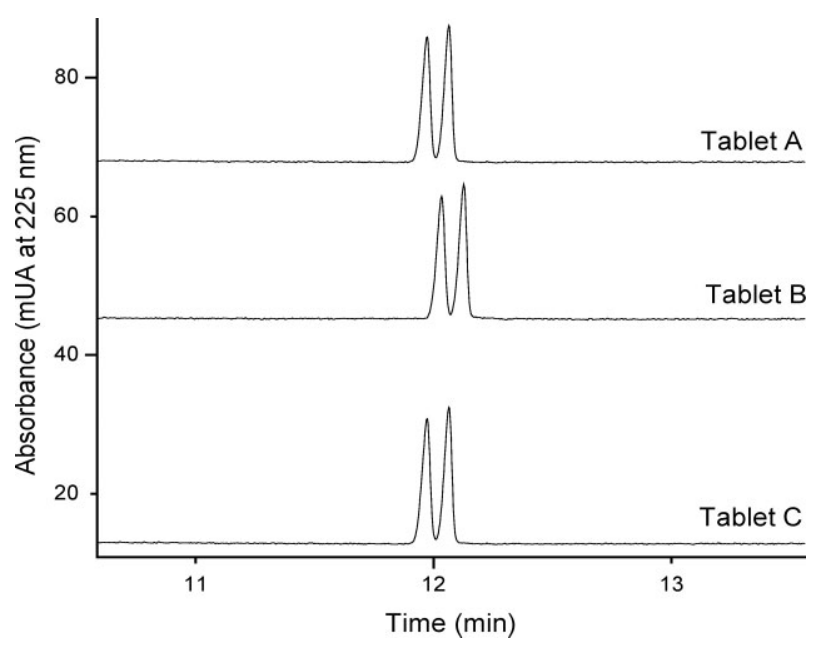

Figure 6. Electropherogram corresponding to the separation of etodolac enantiomers in three different commercial formulations, using $20 \mathrm{~mm}$ HP- $\beta$-CD (DS 4.2) in $100 \mathrm{~mm}$ phosphate buffer (pH 7). CE conditions as in Fig. 4.

ferences due to the other components present in the commercial formulation (see Table 1). In addition, peaks corresponding to etodolac enantiomers in these samples were confirmed by comparison of their UV absorption spectra with those of the standard. It should be taken into account that migration times of tablets are shorter than those of standard solutions. This can be explained by the presence of other components in the pharmaceutical formulations (few minor oxides as illustrated in Table 1) which affects the EOF. It is already known that other components, such as cellulose derivatives, frequently present in tablets, affect the EOF, thereby modifying the migration times in a significant way [26]. However, this problem is easily solved using corrected migration times and areas, as it has been done in this work.

Finally, Table 4 shows the amount of etodolac calculated for the three commercial formulations analyzed. The quantification of etodolac enantiomers confirms that the drug is present in tablets as racemate (1:1 mixture). In addition, results obtained show that the etodolac amount present in tablets is inside the range of the determined amount. Therefore, a good agreement between the amount of etodolac determined by the chiral CE method developed and that declared in the label of the pharmaceutical preparation was observed.

\section{Concluding remarks}

In this work, the possibilities of the randomly substituted HP- $\beta-C D$ as chiral selector for etodolac are presented. Although different enantioresolutions were obtained for this CD with different DSs depending on the supplier (Cyclolab, Fluka, or Sigma), the HP- $\beta$-CD of Fluka (DS 4.2) allowed to obtain a reproducible resolution $>2$ under the applied experimental conditions (100 mM phosphate buffer, $\mathrm{pH} 7.0$, with $20 \mathrm{~mm}$ HP- $\beta$-CD for the CE separation, and UV detection at 225 (10) nm with reference at 360 (50) $\mathrm{nm}$ ). The chiral CE method using the selected conditions was validated to show the quality, reliability, and consistency of its results. Good performance with regard to linearity, instrumental repeatability, method repeatability, intermediate precision, and selectivity was achieved. LODs of $5.8 \mathrm{mg} / \mathrm{L}$ and LOQs of $19.4 \mathrm{mg} / \mathrm{L}$ were obtained for each etodolac enantiomers. The validated method was applied to determine the amount of etodolac enantiomers in three different commercial tablets, being suitable for such purposes.

The authors thank the Ministry of Science and Technology (Spain) for the research project BQU2003-03638 and the University of Alcalá for the research project UAH2002/ 057. C. García-Ruiz also thanks to the Ministry of Science and Technology for the contract from the Ramón y Cajal program. Authors also thank Cyclolab (Budapest, Hungary) for the kind gift of HBen- $\beta-C D^{\circledR}, C E-\beta-C D$, and Ac- $\beta$-CD used in this work and Dr. Laszlo Jicsinsky for his comments during the elaboration of this article.

Received July 30, 2004

Table 4. Averaged amount of etodolac enantiomers and total etodolac measured in the three different commercial formulations analyzed ${ }^{\text {a) }}$

\begin{tabular}{llllll}
\hline $\begin{array}{l}\text { Commercial } \\
\text { formulation }\end{array}$ & $\begin{array}{l}\text { Weight }(\mathrm{mg}) \\
\text { first enantiomer } \\
\pm t s / n^{1 / 2}\end{array}$ & $\begin{array}{l}\text { Weight }(\mathrm{mg}) \\
\text { second enantiomer } \\
\pm t s / n^{1 / 2}\end{array}$ & $\begin{array}{l}\text { Total weight } \\
(\mathrm{mg}) \\
\pm t s / n^{1 / 2}\end{array}$ & $\begin{array}{l}\text { RSD }(\%) \\
\text { Corrected } \\
\text { peak area }\end{array}$ & $\begin{array}{l}\text { Total labeled } \\
\text { weight }(\mathrm{mg})\end{array}$ \\
\hline Tablet A & $105.2 \pm 5.9$ & $105.3 \pm 6.2$ & $210.5 \pm 12.1$ & 7.6 & 200 \\
Tablet B & $157.4 \pm 8.2$ & $157.3 \pm 8.5$ & $314.7 \pm 16.8$ & 7.1 & 300 \\
Tablet C & $156.2 \pm 7.5$ & $156.9 \pm 8.8$ & $313.1 \pm 16.2$ & 6.9 & 300 \\
\hline
\end{tabular}

a) $s$ is the standard deviation, $t=2.262$ (for a confidence linear range of $95 \%$ ), and $n=9$. 


\section{References}

[1] The Comprehensive Resource for Physicians, Drug and IIIness Information, <http://www.rxmed.com/b.main/b2. pharmaceutical/b2.1.monographs/CPS-\%20Monographs/ CPS-\%20(General\%20Monographs-\%20A)/APO_ETODOL AC.html>, checked on July 2004.

[2] Jenson, M., Engert, A., Goebeler, M. E., Weissinger, F., Wilhelm, M., Osterborg, A., Knauf, W., Kimby, E. K., Rosen, P. J., Poynton, C., Rummel, M. J., Hillmen, P., Oliff, I., Kennedy, B., Jullusson, G., Latven, L., Scranton, S. A., Paradiso, L. J., Blood 2003, 102, Abstract 2496.

[3] Netter, P., Lapicque, F., Benzoni, D., Bannwarth, B., Leloet, X., Kuntz, J. L., Schaeverbeke, T., Bertin, P., Gillet, P., Dehais, J., Treves, R., Dropsy, R., Clin. Pharmacol. Ther. 1993, 53, 152-152.

[4] Mignot, I., Presle, N., Lapicque, F., Monot, C., Dropsy, R., Netter, P., Chirality 1996, 8, 271-280.

[5] Brocks, D. R., Jamali, F., Russell, A. S., Skeith, D. J., J. Clin. Pharmacol. 1992, 32, 982-989.

[6] Brocks, D. R., Jamali, F., Clin. Pharmacokinet. 1994, 26, 259-274.

[7] Ali, I., Aboul-Enein, H. Y., Biomed. Chromatogr. 2003, 17, 113-117.

[8] Uray, G., Maier, N. M., Enantiomer 1996, 1, 211-217.

[9] Caccamese, S., Chirality 1993, 5, 164-167.

[10] Beckerscharfenkamp, U., Blaschke, G., J. Chromatogr. B 1993, 621, 199-207.

[11] Fanali, S. (Ed.), Electrophoresis 1999, 20, 2577-2800.
[12] Fanali, S., Chankvetadze, B. (Eds.), Electrophoresis 2001, 22, 3077-3354

[13] Nishi, H., Terabe, S. (Eds.), J. Chromatogr. A 2000, 875, 1471.

[14] Wren, S. A. C. (Ed.), Chromatographia 2001, 54, S5-S93.

[15] Chankvetadze, B., Fanali, S. (Eds.), Electrophoresis 2003, 24, 2407-2732.

[16] Chankvetadze, B., Capillary Electrophoresis in Chiral Analysis, John Wiley \& Sons, Chichester, UK 1997.

[17] Fanali, S., Desiderio, C., Schulte, G., Heitmeier, S., Strickmann, D., Chankvetadze, B., Blaschke, G., J. Chromatogr. A 1998, 800, 69-76.

[18] Mayer, S., Schurig, V., J. Liq. Chromatogr. 1993, 16, 915931.

[19] Currie, L. L. A., Pure Appl. Chem., 1995, 67, 1699-1723.

[20] Mullins, E., Analyst 1999, 124, 433-442.

[21] Martín-Biosca, Y., García-Ruiz, C., Marina, M. L., Electrophoresis 2001, 22, 3216-3225.

[22] Verleysen, K., Sandra, P., Electrophoresis 1998 19, 27982833.

[23] Amini, A., Electrophoresis 2001, 22, 3107-3130.

[24] Bechet, I., Pâques, P., Fillet, M., Hubert, P., Crommen, J., Electrophoresis 1994, 15, 818-823.

[25] Mayer, S., Schurig, V., Electrophoresis 1994, 15, 835-841.

[26] Ekiert, E., García-Ruiz, C., García, M. A., Marina, M. L., Electrophoresis 2003, 24, 2680-2686. 